Elsevier

BBA 72138

\title{
INCREASED EFFICIENCY OF THE OUTER MEMBRANE PhOE PROTEIN PORE IN ESCHERICHIA COLI K-12 MUTANTS WITH HEPTOSE-DEFICIENT LIPOPOLYSACCHARIDE
}

\author{
JAAP KORTELAND * and BEN LUGTENBERG \\ Department of Molecular Cell Biology and Institute for Molecular Biology, State University, Transitorium 3, Padualaan 8, 3584 CH \\ Utrecht (The Netherlands)
}

(Received November 2nd, 1983)

Key words: Outer membrane; PhoE protein; Pore protein; Lipopolysaccharide; Lipoprotein deficiency; (E. coli K.12)

The pore properties of PhoE protein channels in the outer membrane of a lipoprotein-deficient mutant and in a mutant with heptose-deficient lipopolysaccharide were investigated. The absence of lipoprotein neither affects the rate of permeation of glucose 6-phosphate or of the $\beta$-lactam antibiotic cephsulodin through the PhoE pore nor the inhibition of cephsulodin permeation by polyphosphate. In contrast, heptose deficiency results in a 6- to 8-fold increase in the rates of permeation of glucose 6-phosphate and cephsulodin. Possible explanations for these data are discussed. It is argued that the lipopolysaccharide structure synthesized under phosphate limitation may be similar to that of the heptoseless mutant and hence that not only the structure of the PhoE protein pore but also the structure of the lipopolysaccharide may promote the uptake of $P_{i}$ and $\mathbf{P}_{\mathrm{i}}$-containing solutes under phosphate limitation.

\section{Introduction}

The cell envelope of Gram-negative bacteria is composed of three distinct layers: the cytoplasmic membrane, the peptidoglycan layer and the outer membrane. Both membranes contain phospholipid and protein and in addition, the outer membrane contains lipopolysaccharide (for a review see Ref. 1).

Proteins play an important role in the permeability properties of the outer membrane. Escherichia coli $\mathrm{K}-12$ constitutively synthesizes two so-called peptidoglycan-associated proteins, $\mathrm{OmpF}$ and $\mathrm{OmpC}$ protein, which are involved in the formation of non-specific aqueous pores. It has been shown both in vivo and in vitro that these proteins facilitate the diffusion of hydrophilic solutes of a molecular weight up to approximately

* Correspondence should be sent to: Jaap Korteland at the Department of Molecular Cell Biology.
700 daltons across the outer membrane [2-9]. When wild-type cells of $E$. coli $\mathrm{K}-12$ are grown in a medium containing a sub-optimal phosphate concentration, the synthesis of another outer membrane pore protein, PhoE protein, is derepressed [10]. Moreover, these conditions induce the synthesis of a number of other proteins, all of which are involved in the transport of $P_{i}$ and $P_{i}$-containing solutes across the cell envelope $[11,12]$. Constitutive synthesis of $\mathrm{PhoE}$ protein is observed in cells carrying either a phoR, phoS, phoT or pst mutation [12]. PhoE protein shares many properties with $\mathrm{OmpF}$ and OmpC protein. It can be isolated associated with the peptidoglycan layer $[8,13]$ and it is immunologically related to $\mathrm{OmpF}$ and $\mathrm{OmpC}$ protein [14], the latter being consistent with the recently observed strong homology in primary structure between $\mathrm{OmpC}$ protein, $\mathrm{OmpF}$ protein and PhoE protein $[15,16]$. PhoE protein functions as a general pore like $\mathrm{OmpF}$ and $\mathrm{OmpC}$ protein $[6,8,13,17,18]$. Besides general pore properties, 
PhoE protein has a preference for $\mathrm{P}_{\mathrm{i}}$ and $\mathrm{P}_{\mathrm{i}}$-containing solutes as was shown by in vivo transport assays carried out at low solute concentration [19]. By performing the assay at low solute concentrations the rate of permeation through pores in the outer membrane is the rate-limiting step $[4,5,20]$. The recently discovered recognition site for phosphate and also for other negatively charged solutes is likely to be responsible for the efficient uptake of inorganic and organic phosphate [21].

Pore proteins form trimers which interact with lipopolysaccharide. Their attachment to the peptidoglycan layer is probably mainly mediated by lipoprotein molecules (for a review, see Ref. 1). In mutants devoid of lipoprotein severe physiological and morphological alterations occur [22]. Mutants with heptoseless lipopolysaccharide have largely diminished amounts of $\mathrm{OmpF}$ protein [23-26] and PhoE protein [13]. Data of Schindler et al. [27] show that interaction between lipopolysaccharide and $\mathrm{OmpF}$ protein is essential for the functioning of this pore protein.

The established interactions of pore proteins with lipoprotein and with lipopolysaccharide prompted us to investigate whether the functioning of the PhoE protein pore in vivo is influenced by the absence of lipoprotein or by a decreased length of the lipopolysaccharide sugar chain. Both the efficiency of the permeation of glucose 6-phosphate and cephsulodin through the PhoE pore as well as the ability of the PhoE pore to recognize phosphate residues are examined. The present paper describes the results of this study.

\section{Materials and Methods}

Strains, phages, plasmids and growth conditions. All bacterial strains used in this study are derivatives of Escherichia coli K-12. Their sources and relevant characteristics are listed in Table $\mathrm{I}$. The heptose-deficient strains CE1242 and CE1243 were selected as mutants resistant towards lipopolysaccharide-specific phages $T_{3}$ and $T_{7}[25]$. The heptose content of these strains was determined as described [30] and expressed as nmol heptose/mg total cell protein. As heptose deficiency in these mutants does not coincide with proline requirement and therefore is probably not due to a deletion mutation [25], the frequency of revertants producing wild-type lipopolysaccharide was expected to be rather high. However, by starting from fresh single colonies the fraction of revertants, determined on yeast agar plates supplemented with rifampicin in a final concentration of $1 \mu \mathrm{g} / \mathrm{ml}$ [26], could be kept lower than $0.01 \%$. Expression of PhoE protein in a heptoseless lipopolysaccharide background is very poor [13] but could be increased to much higher levels by first introducing the multicopy plasmid pJP12, on which the structural gene for PhoE protein is located, into strain CE1237 by a transformation procedure [31] and subsequently selecting for $T_{3}$ - the $T_{7}$-resistant mutants.

The lipoprotein-deficient derivatives of strain CE1237 were constructed as indicated in Table I. $P_{1}$ transduction was carried out as described in Ref. 32. The presence or absence of lipoprotein was established by the gel immuno radio assay technique as described in Ref. 21. When the uptake of $\beta$-lactam antibiotics was to be measured, $\beta$-lactamase producing strains were constructed by transformation of the appropriate mutant with plasmid pBR322. Except where noted bacterial strains were grown in yeast broth [33] at $37^{\circ} \mathrm{C}$ under vigorous aeration. Cells containing plasmid pJP12 and/or pBR322 were grown in the same medium supplemented with chloramphenicol $(25$ $\mu \mathrm{g} / \mathrm{ml})$ and benzylpenicillin $(50 \mu \mathrm{g} / \mathrm{ml})$, respectively. The lipopolysaccharide-specific phages $\mathrm{P}_{1}$, $\mathrm{T}_{3}$ and $\mathrm{T}_{7}$ and the $\mathrm{PhoE}$ protein specific phage TC45 were from laboratory stocks.

Isolation and characterization of cell fractions. Cell envelopes were isolated by differential centrifugation after ultrasonic treatment of the cells [34]. The cell envelope protein patterns were analyzed by SDS (sodium dodecyl sulphate)-polyacrylamide gel electrophoresis [34]. Protein was determined according to Lowry et al. [35].

In order to determine the relative amount of PhoE protein per cell, the proteins associated with the peptidoglycan layer were separated from the other cell envelope proteins by ultracentrifugation after extraction of the cell envelopes at $60^{\circ} \mathrm{C}$ in buffer containing $2 \%$ SDS $[36,37]$. The proteinpeptidoglycan complexes were analyzed on a polyacrylamide gel and the protein pattern on the gel was scanned with a Vitatron TLD100 densitometer. As the accuracy of the gel scanning is depen- 
TABLE I

BACTERIAL STRAINS

Genotype descriptions follow recommendations of Bachmann and Low [28] except for phoE which represents the structural gene for PhoE protein [29].

\begin{tabular}{|c|c|c|c|c|c|}
\hline \multirow[t]{2}{*}{$\overline{\text { Strain }}$} & \multirow[t]{2}{*}{ Relevant characteristics } & \multicolumn{3}{|c|}{ Relevant protein pattern } & \multirow{2}{*}{$\begin{array}{l}\text { Source, } \\
\text { reference }\end{array}$} \\
\hline & & $\mathrm{OmpF}$ & OmpC & $\overline{\text { PhoE }}$ & \\
\hline CE1237 & $\begin{array}{l}\mathrm{F}^{-}, \text {thi, pyrF, thy, ilvA, his, } \\
\text { lac } Y, \text { argG, ton } A, \text { tsx }, \text { rps } L \\
\text { cod, dra, vir, glp } R, \text { phoR } 69 \\
\text { phoA8, ompB } 471\end{array}$ & - & - & + & [19] \\
\hline CE1238 & $\begin{array}{l}\text { TC45 resistant phoE, pro } \\
\text { derivative of strain CE1237 }\end{array}$ & - & - & - & [19] \\
\hline CE1239 & $\begin{array}{l}\text { SDS-resistant derivative } \\
\text { of strain CE1238 }\end{array}$ & + & + & - & [19] \\
\hline CE1242 & $\begin{array}{l}\text { heptose-deficient lipopoly- } \\
\text { saccharide mutant of strain } \\
\text { CE1237 }\end{array}$ & - & - & + & This study \\
\hline CE1243 & $\begin{array}{l}\text { heptose-deficient lipopoly- } \\
\text { saccharide mutant of strain } \\
\text { CE1238 }\end{array}$ & - & - & - & This study \\
\hline JE5513 & HfrC, lpo5508, manA, pps & + & + & - & [22] \\
\hline CE1244 & $\begin{array}{l}\text { lpo5508, manA } A^{+} \text {derivative } \\
\text { of strain JE5513 obtained } \\
\text { by transduction with a } P_{1} \\
\text { lysate of strain CE1237 }\end{array}$ & + & + & - & This study \\
\hline CE1245 & $\begin{array}{l}\text { EMS }^{\text {a }} \text { induced } \operatorname{man} A, l p o^{+} \\
\text {derivative of strain CE1237 }\end{array}$ & - & - & + & This study \\
\hline CE1246 & $\begin{array}{l}\operatorname{man} A^{+}, \text {lpo5508 derivative } \\
\text { of strain CE1245 obtained } \\
\text { by transduction with a } P_{1} \\
\text { lysate of strain CE1244 }\end{array}$ & - & - & + & This study \\
\hline CE1247 & $\begin{array}{l}\text { TC45 resistant phoE, pro } \\
\text { derivative of strain CE1 } 246\end{array}$ & - & - & - & This study \\
\hline
\end{tabular}

a EMS is the abbreviation for ethyl methane sulphonate.

dent on the intensity of the protein band, amounts of 1-3 $\mu \mathrm{g}$ of protein were applied per slot. In this range the surface area of the PhoE protein peaks was proportional with the amount of PhoE protein applied. Data for the relative amounts of PhoE protein per cell were calculated from the gel scans and expressed as $\mu \mathrm{g}$ PhoE protein per mg total cell protein.

Transport studies. The rate of permeation of D- $\left\{\mathrm{U}-{ }^{14} \mathrm{C}\right] \mathrm{glucose}$ 6-phosphate through the PhoE protein pore was determined as described [19] and expressed as $\mathrm{nmol} / \mathrm{min}$ per $\mu \mathrm{g}$ pore protein. In all uptake experiments control samples of the cell suspensions were used for the determination of the heptose content and the relative amount of PhoE protein per cell. The latter value was somewhat variable in heptoseless mutants. Surprisingly, this variation was independent of the reversion frequency. The cell envelope protein pattern was also used to check whether the pore protein pattern of the strains was unaltered.

Assays for the rate of permeation of cephsulodin across the outêr membrane have been described repeatedly $[6,38,39]$. In order to measure the rate of uptake through the PhoE pore, we used the modified method introduced by Overbeeke and Lugtenberg [21]. Cephsulodin uptake was measured at cell concentrations of $2 \cdot 10^{8}$ cells $/ \mathrm{ml}$, with the exception of heptose-deficient and poredeficient mutants, for which concentrations of 5 . $10^{8}$ and $9 \cdot 10^{8}$ cells per $\mathrm{ml}$, respectively, were used. Control cell suspensions were analyzed as 
described in the previous section. Cephsulodin was present in a final concentration of $0.8 \mathrm{mM}$ and the inhibitory effect of polyphosphate type P15 was tested at a concentration of $0.2 \mathrm{mM}$. Total $\beta$ lactamase activity was determined after converting cells to spheroplasts using the method of Osborn et al. [40]. To check for the leakage of $\beta$-lactamase activity during the assay, cells were incubated without antibiotic for various periods of time followed by the determination of the $\beta$-lactamase activity in the assay fluid obtained after separating the fluid from the cells by membrane filtrations (Millipore, type HA, pore diameter $0.45 \mu \mathrm{m}$ ).

All uptake experiments were carried out at solute concentrations equal to or lower than the apparent $K_{\mathrm{m}}$ value for strain CE1237 in order to ascertain that permeation through the outer membrane is the rate-limiting step.

Chemicals. $\mathrm{D}-\left[\mathrm{U}-{ }^{14} \mathrm{C}\right]$ Glucose 6-phosphate was purchased from The Radiochemical Centre, Amersham, Bucks, U.K. Cephsulodin was a generous gift from Dr. W. Zimmerman (Ciba Geigy AG, Basle, Switzerland). Polyphosphate type P15 was purchased from Sigma Chemical Company (St. Louis, MO, U.S.A.).

\section{Results}

Strain construction and cell envelope protein patterns

As a result of the ompB $B 71$ mutation, strain CE1237 lacks the pore proteins OmpF protein and OmpC protein. Although in wild-type cells the synthesis of PhoE protein is only induced by phosphate limitation, strain CE1237 produces PhoE protein constitutively due to a phoR mutation. Consequently PhoE protein is the only pore protein synthesized by strain CE1237 (Fig. 1a). Moreover, due to a phoA mutation, alkaline phosphatase activity is lacking in this strain which makes it suitable for measuring the rate of uptake of organic phosphate across the outer membrane without prior degradation of substrate due to leakage of small amounts of the enzyme into the medium [19]

As expected from previous results [13], strain CE1242, the heptose-deficient derivative of strain CE1237, contains strongly decreased amounts of PhoE protein (Fig. 1b). Uptake experiments with

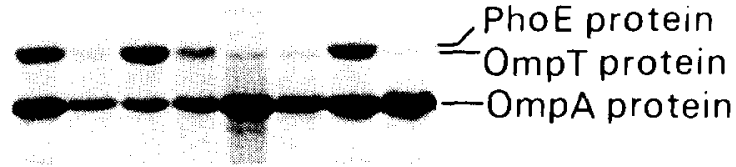

$a \quad b \quad c \quad d e f g h$

Fig. 1. Cell envelope protein patterns obtained by SDS-polyacrylamide gel electrophoresis. The cell envelopes of the strains were prepared from the same batches of cells as were used for the uptake studies of which the data are listed in Table II. The slots contain preparations of the following strains, (a) CE1237, (b) CE1242, (c) CE1237 transformed with plasmid pJP12, (d) CE1242 transformed with plasmid pJP12, (e) CE1238, (f) CE1243, (g) CE1246, (h) CE1247. Only the relevant part of the gel is shown. The pore proteins $\mathrm{OmpC}$ protein and $\mathrm{OmpF}$ protein, absent in the cell envelopes of the strains shown in this figure, run in positions in between OmpT protein and OmpA protein.

this strain were not successful as the amount of PhoE protein was too small to measure significant permeation of substrates across the outer membrane of the heptose-deficient strain. The amount of PhoE protein in the heptose-deficient background was increased by first transforming strain CE1237 with the multicopy plasmid pJP12, on which the structural gene for PhoE protein is located and subsequently selecting for $\mathrm{T}_{3^{-}}$and $T_{7}$-resistant mutants. Analysis of the cell envelope protein pattern shows that the presence of the multicopy plasmid results in the synthesis of high levels of PhoE protein in strain CE1237 (Fig. 1c) whereas the heptose-deficient strain also contains considerable amounts of PhoE protein (Fig. 1d). The pore-deficient strains CE1238 (Fig. le) and CE1243 (Fig. 1f) with wild-type and heptose-deficient lipopolysaccharide, respectively were constructed to check whether the measured permeability was indeed related to the presence of $\mathrm{PhoE}$ protein in the outer membrane.

The cell envelope protein pattern of the lipoprotein-deficient mutant CE1246 (Fig. 1g) shows that the level of expression of $\mathrm{PhoE}$ protein is hardly or not at all influenced by the absence of lipoprotein. The pore protein deficient derivative of strain CE1246, strain CE1247 (Fig. 1h), was constructed in order to relate the permeation of solutes in the lipoproteinless mutant to the presence of PhoE pore protein in the outer membrane. 
TABLE II

INFLUENCE OF SHORTENING OF THE LIPOPOLYSACCHARIDE SUGAR CHAIN AND OF THE LACK OF LIPOPROTEIN ON CHANNEL PROPERTIES OF PhOE PROTEIN

\begin{tabular}{|c|c|c|c|c|c|c|c|}
\hline \multirow[t]{5}{*}{ Strain $^{2}$} & \multicolumn{4}{|c|}{ Phenotype } & \multirow{2}{*}{\multicolumn{3}{|c|}{$\begin{array}{l}\text { Rate of uptake by intact cells } \\
(\mathrm{nmol} / \mathrm{min} \mu \mathrm{g} \text { pore protein) }\end{array}$}} \\
\hline & \multicolumn{2}{|c|}{ Pore protein } & \multirow[t]{4}{*}{ Heptose $^{b}$} & \multirow{4}{*}{$\begin{array}{l}\text { Lipo- } \\
\text { protein }\end{array}$} & & & \\
\hline & \multirow{3}{*}{ Type(s) } & \multirow{3}{*}{$\begin{array}{l}\mu \mathrm{g} \text { per } \\
\mathrm{mg} \text { total } \\
\text { cell pro- } \\
\text { tein }\end{array}$} & & & \multirow{3}{*}{$\begin{array}{l}\text { Glucose 6- } \\
\text { phosphate } \\
(1.0 \mu \mathrm{M})\end{array}$} & \multicolumn{2}{|c|}{ Cephsulodin $(0.8 \mathrm{mM})$} \\
\hline & & & & & & \multicolumn{2}{|c|}{ Poly-P type P15 $(0.2 \mathrm{mM})$} \\
\hline & & & & & & - & + \\
\hline CE1237 & PhoE & 41 & + & + & 0.11 & 9.1 & $3.2(65)^{d}$ \\
\hline \multicolumn{8}{|l|}{ CE1242/ } \\
\hline pJP12 & PhoE & 5 & - & + & 0.62 & 78 & $18 \quad(77)$ \\
\hline CE1243 & 'none' & $<1$ & - & + & $<0.01$ & $<0.1$ & $<0.1$ (n.d.) \\
\hline CE1246 & PhoE & 38 & + & - & 0.10 & 8.7 & 2.8 (n.d.) \\
\hline CE1247 & 'none' & $<1$ & + & - & $<0.01$ & $<0.1$ & $<0.1$ (n.d.) \\
\hline \multirow[t]{2}{*}{ CE1239 } & OmpF & 49 & + & + & n.d. ${ }^{e}$ & 15.2 & $14.9(2)$ \\
\hline & OmpC & & & & & & \\
\hline
\end{tabular}

a High $\beta$-lactamase activity necessary for measuring the uptake of cephsulodin was obtained by transforming plasmid pBR322 into the appropriate strains.

b The average heptose content of the strains containing wild-type lipopolysaccharide was calculated as $0.12 \mu \mathrm{mol} / \mathrm{mg}$ total cell protein. The amount of heptose produced in the heptose-deficient strain was always less than $5 \%$ of the amount produced by strains containing wild-type lipopolysaccharide.

c The uptake data are the average of at least four experiments.

d These data represent the percentages of inhibition by polyphosphate. The percentages were calculated as $100 \times$ (uptake without inhibitor - uptake in the presence of inhibitor)/uptake without inhibitor.

e n.d., not determined.

Influence of the lipopolysaccharide sugar chain and of lipoprotein on the channel properties of PhoE protein

Recent experiments have shown that $P_{i}$ and $\mathrm{P}_{\mathrm{i}}$-containing solutes preferentially permeate through the PhoE protein pore [19]. In order to investigate a possible change in the efficiency of the PhoE pore for $\mathrm{P}_{\mathrm{i}}$-containing solutes, the rate of permeation of glucose 6-phosphate across the outer membrane of various strains was determined. Experiments with cells containing increased amounts of PhoE protein, due to the presence of the multicopy plasmid pJP12 revealed that the rate of permeation of glucose 6-phosphate increases directly proportional with the amount of PhoE protein produced (not shown). Consequently, permeation through PhoE pores, produced by strain CE1237 without plasmid pJP12, is rate-limiting. The results (Table II) show that the rate of permeation through the PhoE pore in the parental strain CE1237 is 5-to 6-fold lower than that through the PhoE pore in the heptose-deficient strain CE1232. A similar effect of heptose deficiency was found for the rate of permeation of cephsulodin (Table II). Control experiments with the heptoseless, pore-deficient strain CE 1243 indicate that there is no significant pore activity across the outer membrane in the absence of PhoE protein. Thus, the lack of the lipopolysaccharide core sugars makes the PhoE pore about 6- to 8-fold more efficient in the uptake of glucose 6-phosphate and cephsulodin. In contrast to heptose deficiency, the absence of lipoprotein hardly influences the permeation of the two solutes through the PhoE pore (Table II).

In order to test the influence of heptose-deficient and lipoprotein-deficient backgrounds on the ability of $\mathrm{PhoE}$ protein to recognize phosphate moieties, the rate of permeation of cephsulodin was determined in the presence of polyphosphate type P15. The results in Table II show that cephsulodin uptake through the PhoE protein pore in strain CE1237 is inhibited by polyphosphate type $P 15$, whereas there is no inhibitory effect on the rate of permeation of cephsulodin in strain CE1239 
containing both OmpF and OmpC proteins but lacking the PhoE protein. This PhoE protein specific effect is also found for mutants deficient in heptose or lipoprotein.

\section{Discussion}

By reconstitution of OmpF protein trimers into planar lipid bilayers it was shown that lipopolysaccharide is required for pore activity in these phospholipid bilayers [27]. However, it should be noted that pore activity in artificial (outer) membranes cannot be simply compared to pore activity in the cell. In vivo, at least the lipid A part of lipopolysaccharide together with 2-keto-3-deoxyoctonate is essential for growth of the cell. So, in vivo studies on the influence of lipopolysaccharide on the pore function of the pore proteins are mainly limited to variations in the core sugar chain of lipopolysaccharide. A structural role of lipoprotein for the assembly and/or integrity of the outer membrane has been reported $[22,41]$ and evidence for an interaction between lipoprotein and pore protein has been presented [1,42].

To investigate the influence of lipoprotein and lipopolysaccharide on the functioning of the PhoE protein pore, lipoprotein-deficient and heptose-deficient mutants were constructed. The absence of lipoprotein does not seem to affect the expression of PhoE protein (Fig. 1, compare slots a and g). The expression of PhoE protein in the heptose-deficient background is strongly reduced, suggesting that the lipopolysaccharide sugar chain is involved in the interaction of lipopolysaccharide with $\mathrm{PhoE}$ protein. The lack of expression of PhoE protein in heptose-deficient strains can be overcome by the presence of multiple copies of the phoE gene (Fig. 1 , compare slots $b$ and $d$ ). This observation allowed us to study the influence of the presence of the core sugars on the functioning of the PhoE pore.

As far as the pore function of PhoE protein is concerned two observations indicate that in vivo PhoE protein, in addition to having channel properties, has some more or less specific properties. Firstly, PhoE protein is especially effective in facilitating the diffusion of $\mathrm{P}_{i}$ and $\mathrm{P}_{i}$-containing solutes across the outer membrane [19]. Secondly, PhoE protein is able to recognize $P_{i}$ and also other negatively charged solutes [21]. The present results show that, whereas the absence of lipoprotein does not significantly affect the rates of permeation of glucose 6-phosphate and cephsulodin through the PhoE protein pore, the lack of heptose and the more distal core sugars result in a 6- to 8-fold more efficient permeation of the mentioned solutes (Table II). The results also show that neither the lack of the lipopolysaccharide core sugars nor the absence of lipoprotein grossly influence the recognition of solutes as measured by inhibition of cephsulodin uptake by polyphosphate (Table II).

On the molecular level at least three explanations can be given for the increased efficiency of the PhoE pore in strains missing such a large part of the lipopolysaccharide sugar chain. (i) The reduced length of the lipopolysaccharide may lead to a conformational change of the PhoE protein and hence to an increased effective diameter of the pore. Our results show that the recognition site is not essentially influenced by such a proposed conformation change. If the effective diameter of the PhoE pore was indeed increased one would predict that the rate of permeation of ampicillin, which permeates very slowly through $\mathrm{PhoE}$ protein pores in a background with wild-type lipopolysaccharide [6], would be considerably more increased in a heptoseless lipopolysaccharide background than that of cephsulodin. However, preliminary experiments show that this is not the case (results not shown). (ii) As the pores are supposed to exist in a dynamic equilibrium of two states, closed and open [9], the number of open, functional PhoE protein pores could be increased in the heptose-deficient mutant. In this respect it should be noted that Kropinski et al., [43] favour the idea that in Pseudomonas aeruginosa the number of open functional pores and hence the outer membrane permeability is influenced by the state of the lipopolysaccharide. (iii) In heptoseless mutants the pore could be more accessible for the solutes because of the absence of steric hindrance by the lipopolysaccharide core sugars. Moreover, the loss of heptose coincides with the loss of phosphate groups bound to this sugar [44]. The reduction of the number of these strongly negatively charged residues may be favourable for the permeation of negatively charged solutes as the repulsive forces between these phosphate residues and negatively charged solutes are absent.

Phosphate limitation, the natural condition 
which induces PhoE protein, must be expected to influence the structure of the lipopolysaccharide molecule in a way similar to the mutation which causes heptose-deficiency. From the results of a study on the biosynthesis of Salmonella typhimurium lipopolysaccharide it was concluded that phosphorylation of heptose is necessary for galactose transfer and for the introduction of an ethanolamine pyrophosphate group into the core [45]. Thus it is likely that also in vivo phosphate limitation results in the synthesis of lipopolysaccharide with a deficiency in phosphate and therefore with a reduced length of the core sugar chain. The predicted similarities between heptoseless lipopolysaccharide and the lipopolysaccharide structure synthesized under phosphate limitation strongly suggests that the increase in efficiency in the functioning of the PhoE protein pore in heptoseless mutants may reflect the actual situation under phosphate limitation. Thus two factors in the outer membrane may favour the uptake of $\mathbf{P}_{i}$ and $\mathbf{P}_{i}$-containing solutes, namely the replacement of the general pore proteins by the more efficient [19] PhoE protein pore and, at the same time, the synthesis of a modified lipopolysaccharide structure that greatly improves the permeability of the PhoE protein for $\mathrm{P}_{\mathrm{i}}$-containing and other negatively charged solutes.

\section{Acknowledgement}

We thank Lilian Joosen for her help with the construction of the strains.

\section{References}

1 Lugtenberg, B. and Van Alphen, L. (1983) Biochim. Biophys. Acta 737, 51-115

2 Nakae, T. (1976) Biochem. Biophys. Res. Commun. 71, 877-884

3 Nakae, T. (1976) J. Biol. Chem. 251, 2176-2178

4 Beacham, I.R., Haas, D. and Yagil, E. (1977) J. Bacteriol. $129,1034-1044$

5 Lutkenhaus, J.F. (1977) J. Bacteriol. 131, 631-637

6 Van Alphen, W., Van Boxtel, R., Van Selm, N. and Lugtenberg, B. (1978) FEMS Microbiol. Lett. 3, 103-106

7 Benz, R., Janko, K., Boos, W. and Läuger, P. (1978) Biochim. Biophys. Acta 511, 305-319

8 Van Alphen, W., Van Selm, N. and Lugtenberg, B. (1978) Mol. Gen. Genet. 159, 75 -83

9 Schindler, H. and Rosenbusch, J.P. (1978) Proc. Natl. Acad. Sci. U.S.A. $75,3751-3755$
10 Overbeeke, N. and Lugtenberg, B. (1980) FEBS Lett. 112 229-232

11 Tommassen, J. and Lugtenberg, B. (1982) Ann. Microbiol. (Inst. Pasteur) 133A, 243-249

12 Tommassen, J. and Lugtenberg, B. (1980) J. Bacteriol. 143, 151-157

13 Lugtenberg, B., Van Boxtel, R., Verhoef, C. and Van Alphen, W. (1978) FEBS Lett. 96, 99-105

14 Overbeeke, N., Van Scharrenburg, G. and Lugtenberg, B. (1980) Eur. J. Biochem. 110, 247-254

15 Overbeeke, N., Bergmans, H., Van Mansfeld, F. and Lugtenberg, B. (1983) J. Mol. Biol. 163, 513-532

16 Mizuno, T., Chou, M. and Inouye, M. (1983) J. Biol. Chem. 258, 6932-6940

17 Foulds, J. and Chai, T. (1978) J. Bacteriol. 133, 1478-1483

18 Pugsley, A.P. and Schnaitman, C.A. (1978) J. Bacteriol. 135, 1118-1129

19 Korteland, J., Tommassen, J. and Lugtenberg, B. (1982) Biochim. Biophys. Acta 690, 282-289

20 Nikaido, H. (1979) in Bacterial Outer Membranes: Biogenesis and Functions (Inouye, M., ed.), pp. 361-407, WileyInterscience, New York

21 Overbeeke, N. and Lugtenberg, B. (1982) Eur. J. Biochem. 126, 113-118

22 Suzuki, H., Nishimura, Y., Yasuda, S., Nishimura, A., Yamada, M. and Hirota, Y. (1978) Mol. Gen. Genet. 167, 1-9

23 Ames, G.F., Spudich, E.N. and Nikaido, H. (1974) J. Bacteriol. 117, 406-416

24 Koplow, J. and Goldfine, H. (1974) J. Bacteriol. 117, 527-543

25 Havekes, L.M., Lugtenberg, B.J.J. and Hoekstra, W.P.M. (1976) Mol. Gen. Genet. 146, 43-50

26 Van Alphen, W., Lugtenberg, B. and Berendsen, W. (1976) Mol. Gen. Genet. 147, 263-269

27 Schindler, H. and Rosenbusch, J.P. (1981) Proc. Natl. Acad. Sci. U.S.A. 78, 2302-2306

28 Bachmann, B.J. and Low, K.B. (1980) Microbiol. Rev. 44, $1-56$

29 Tommassen, J. and Lugtenberg, B. (1981) J. Bacteriol. 147, $118-123$

30 Osborn, M.J. (1963) Proc. Natl. Acad. Sci. U.S.A. 50, 499-506

31 Brown, M.G., Weston, M.A., Saunders, J.R. and Humphreys, G.O. (1979) FEMS Microbiol. Lett. 5, 219-222

32 Willetts, N.S., Clark, A.J. and Low, K.B. (1969) J. Bacteriol. 97, 244-249

33 Lugtenberg, B., Peters, R., Bernheimer, H. and Berendsen, W. (1976) Mol. Gen. Genet. 147, 251-262

34 Lugtenberg, B., Meyers, J., Peters, R., Van der Hoek, P. and Van Alphen, L. (1975) FEBS Lett. 58, 254-258

35 Lowry, O.H., Rosebrough, N.J., Farr, A.L. and Randall, R.J. (1951) J. Biol. Chem. 193, 265-275

36 Rosenbusch, J.P. (1974) J. Biol. Chem. 249, 8019-8029

37 Lugtenberg, B., Bronstein, H., Van Selm, N. and Peters, R. (!977) Biochim. Biophys. Acta 465, 571-578

38 Zimmerman, W. and Rosselet, A. (1977) Antimicrob. Agents Chemother. 12, 368-372 
39 Nikaido, H., Song, S.A., Shaltiel, L. and Nurminen, M. (1977) Biochem. Biophys. Res. Commun. 76, 325-330

40 Osborn, M.J., Gander, J.E., Parisi, E. and Carson, J. (1972) J. Biol. Chem. 247, 3962-3972

41 Sonntag, I., Schwarz, H., Yukinori, H. and Henning, U. (1978) J. Bacteriol. 136, 280-285

42 De Martini, M. and Inouye, M. (1978) J. Bacteriol. 133, 329-335
43 Kropinski, A.M., Kuzio, J., Angus, B.L. and Hancock, R.E.W. (1982) Antimicrob. Agents Chemother. 21, 310-319 44 Boman, H.G. and Monner, D.A. (1975) J. Bacteriol. 121, 455-464

45 Mühlradt, P.F. (1971) Eur. J. Biochem. 18, 20-27 